\title{
COMPONENT WEDGE-SPLITTING/BENDING TEST OF NOTCHED SPECIMENS WITH VARIOUS CRACK-TIP CONSTRAINT CONDITIONS: EXPERIMENTS AND SIMULATIONS
}

\author{
VÁCLAV VESELÝ ${ }^{*}$, ILDIKO MERTA ${ }^{\dagger}$, HANA ŠIMONOVÁ, ANDREAS SCHNEEMAYER ${ }^{\dagger}$, \\ STANISLAV SEITL ${ }^{\dagger \dagger}$ AND ZBYNĚK KERŠNER * \\ Brno University of Technology, Faculty of Civil Engineering, \\ Institute of Structural Mechanics, Brno, Czech Republic \\ e-mail: vesely.v1@fce.vutbr.cz, simonova.h@fce.vutbr.cz,kersner.z@fce.vutbr.cz \\ ${ }^{\dagger}$ TU Wien, Faculty of Civil Engineering, Institute of Building \\ Construction and Maintenance, Vienna, Austria \\ e-mail: ildiko.merta@tuwien.ac.at, andreas.schneemayer@tuwien.ac.at \\ ${ }^{\dagger}$ Institute of Physics of Materials, Academy of Sciences \\ of the Czech Republic, v. v. i., Brno, Czech Republic \\ e-mail: seitl@ipm.cz
}

Key words: Fracture test, Wedge splitting, Three-point bending, Crack-tip stress constraint, Normal concrete, Cohesive crack simulations

\begin{abstract}
The paper presents a fracture-mechanics study conducted on a novel test configuration based on a combination of the wedge splitting and the bending test geometry. Four variants of this configuration differing in parameters of the specimen shape and boundary conditions were considered in the study. These selected variants exhibit significantly different stress state conditions at the crack tip, or, more generally, in the whole specimen ligament. The variation of the crack-tip stress constraint is of a crucial importance for the study because the expected differences in the fracture process zone extent and the amount of energy dissipation related to this zone is of particular interest here. An extensive experimental campaign was conducted on concrete specimens made of the same mixture. Processing and evaluation of the test data using the standard work of fracture technique was accompanied with numerical simulations by means of finite elements with implemented cohesive crack model to correlate the amount of energy dissipation with the simulated damaged zone extent. Variations of the fracture energy and also the stress/inelastic strain distribution with the change of the crack-tip constraint parameter and the notch length are observed.
\end{abstract}

\section{INTRODUCTION, MOTIVATION}

A novel method for evaluation of fracturemechanical parameters of quasi-brittle cementitious composites was introduced recently [1] by the Brno University of Technology (BUT) partner of the joint research presented in this paper. The method should eliminate drawbacks of most of the established models for determination of those characteristics, which is the dependence of values the fracture properties determined from fracture tests on laboratory specimens on the specimen size, geometry and its boundaries. Capturing these effects shall be achieved via a detailed incorporation of the fracture process zone (FPZ) existence into the evaluation 
procedure. Results of the method may be regarded as very promising up to now [1]-[3], however, it still lacks a sound experimental validation. And this is caused by the fact that most experimental data available in literature are either/both obtained from tests with a limited range of crack-tip constraint levels (i.e. the FPZ shape/size does not differ as much as it would be necessary to become conspicuous and take it into account for the fracture behaviour evaluation [4]-[9]) or/and processed into a form that is not suitable for validation of the method (cumulative extents of the failure zone are mainly published instead of the current ones needed [10]-[13]).

An experimental campaign focused on investigation of fracture processes in cases with various extents of FPZ (widths, lengths, of various shapes), and thus various progresses of energy dissipation within it, was conducted at Vienna University of Technology (TU Wien, TUW) to validate the above-mentioned method and compare obtained results to the existing fracture-mechanics models. A completely novel geometry utilizing combined boundary conditions of the well-known and standardized Wedge Splitting test (WST) [14],[15] and Three-Point Bending (TPB) test [16] (or Four-Point Bending - FPB) test was proposed in this research. There was no such test so far published in the literature.

The paper presents selected results of this new experimental campaign, description of their processing and analysis as well as some numerical simulations accompanying preparation and evaluation of this experimental work.

\section{EXPERIMENTS}

\subsection{Test configuration}

The novel combined WST/TPB test geometry proposed for this campaign (numerically investigated in [17],[18]) provides a wide range of various stress distributions in the specimen ligament - from bending to tension with (very) low eccentricity - which is expected to result in the desired variety in the FPZ size and shape. These changes in the stress field can be obtained via tuning the specimen length to width and the span to length ratios (and/or simultaneously the wedge angle).

Schemes of variants of the test geometry selected for the experimental study are shown in Fig. 1. Variant I represents the classical WST and is included in the study as a reference case. In the variants II and III, the specimens of the length to width ratios equal to 2 and 4, respectively, are used. In all these cases, the crack propagates from a notch provided on the top side (in the groove for inserting of the WST loading fixtures). Finally, the variant IIIb differs from the variant III by the central notch provided also from the bottom surface. Moreover, loading wedges of two slope angles were used within the WST loading mechanism. Two or three notch lengths, depending on the geometry variant, were considered.

Dimensions of tested specimens corresponding to nomenclature used in Fig. 1 for all four geometry variants are summarized in Tab. 1 (dimensions common to all variants) and Tab. 2 (dimensions special for the individual variants and their subsets).

\subsection{Material of specimens and their testing}

The designed composition of the tested cementitious composite corresponds to normal concrete. The aggregate used for the mix was limestone gravel with maximum particle size of $4 \mathrm{~mm}$ for the fine aggregate (sand) and $11 \mathrm{~mm}$ for the coarse aggregate. Cement

Table 1: Nominal specimen dimensions and test geometry parameters (common for var. I to var. IIIb)

\begin{tabular}{ccccccccc}
\hline width & breadth & height & $\begin{array}{c}\text { load } \\
\text { position }\end{array}$ & $\begin{array}{c}\text { groove } \\
\text { depth }\end{array}$ & $\begin{array}{c}\text { effective } \\
\text { width }\end{array}$ & $\begin{array}{c}\text { groove } \\
\text { width }\end{array}$ & $\begin{array}{c}\text { load } \\
\text { position }\end{array}$ & eccentricity \\
\hline$W$ & $B$ & $H$ & $h$ & $d_{\mathrm{n}}$ & $W_{\mathrm{ef}}$ & $f$ & $i$ & $e$ \\
\hline$[\mathrm{mm}]$ & {$[\mathrm{mm}]$} & {$[\mathrm{mm}]$} & {$[\mathrm{mm}]$} & {$[\mathrm{mm}]$} & {$[\mathrm{mm}]$} & {$[\mathrm{mm}]$} & {$[\mathrm{mm}]$} & {$[\mathrm{mm}]$} \\
\hline 150 & 150 & 130 & 8 & 20 & 142 & 40 & 10 & 20 \\
\hline
\end{tabular}


Table 2: Nominal specimen dimensions and test geometry parameters (special for individial variants)

\begin{tabular}{ccccccccc}
\hline $\begin{array}{c}\text { geometry } \\
\text { variant, } \\
\text { specimen } \\
\text { set }\end{array}$ & $\begin{array}{c}\text { number of } \\
\text { specimens }\end{array}$ & $\begin{array}{c}\text { wedge } \\
\text { angle }\end{array}$ & length & span & $\begin{array}{c}\text { depth of } \\
\text { top } \\
\text { notch }\end{array}$ & $\begin{array}{c}\text { depth of } \\
\text { bottom } \\
\text { notch }\end{array}$ & $\begin{array}{c}\text { initial } \\
\text { crack } \\
\text { length }\end{array}$ & $\begin{array}{c}\text { relative } \\
\text { crack } \\
\text { length }\end{array}$ \\
\hline I, $\alpha_{1}$ & 6 & 30 & 150 & 0 & 13 & - & 25 & 0.18 \\
I, $\alpha_{2}$ & 6 & 30 & 150 & 0 & 30 & - & 42 & 0.30 \\
\hline II, $\alpha_{1}$ & 3 & 15 & 300 & 270 & 15 & - & 27 & 0.19 \\
II, $\alpha_{2}$ & 6 & 15 & 300 & 270 & 31 & - & 43 & 0.30 \\
II, $\alpha_{3}$ & 3 & 15 & 300 & 270 & 54 & - & 66 & 0.46 \\
\hline III, $\alpha_{1}$ & $3(1+2)$ & 30,15 & 600 & 540 & 13 & - & 25 & 0.18 \\
III, $\alpha_{2}$ & 6 & 15 & 600 & 540 & 35 & - & 47 & 0.33 \\
III, $\alpha_{3}$ & 3 & 15 & 600 & 540 & 54 & - & 66 & 0.46 \\
\hline IIIb, $\alpha_{2}$ & $6(3+3)$ & 15,30 & 600 & 540 & 8 & 53 & 53 & 0.37 \\
IIIb, $\alpha_{3}$ & 6 & 30 & 600 & 540 & 9 & 81 & 81 & 0.57 \\
\hline
\end{tabular}

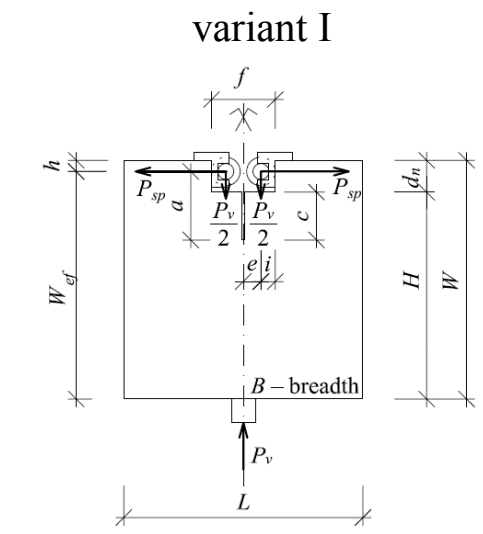

variant II

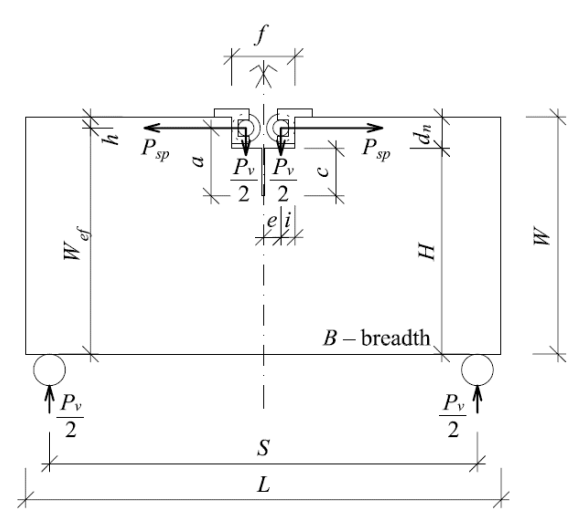

Figure 1: Considered variants of the component wedge-splitting/bending loading test configuration.

CEM II/42.5N was used with a water to cement ratio of $w / c=0.4$. The cement to sand to coarse aggregate ratio was equal to 1 to 1.5 to 2.5. The concrete was mixed by a laboratory drum-mixer and compacted on a vibrating table. The specimens were demoulded
24 hours after casting and stored in water until testing at the age of 12 to 16 days. The concrete has compression cube strength of $31.44 \mathrm{~N} / \mathrm{mm}^{2}$ at that age (mean value of 48 measurements on the broken fragments of the specimens subjected to the fracture test). 
The tests were carried out in laboratory of TU Wien, at the Department of Building Construction and Technology (Centre of Building Construction and Rehabilitation). An INSTRON mechanical testing machine with a load capacity of $100 \mathrm{kN}$ and a stiffness of $125 \mathrm{kN} / \mathrm{mm}$ was employed. The cross-head speed was kept constant with $0.5 \mathrm{~mm} / \mathrm{min}$ for most of the tests, the rate was decreased to $0.2 \mathrm{~mm} / \mathrm{min}$ for the IIIb, $\alpha_{3}$ set only (due to rather instable behaviour, see below). The used loading rate corresponds roughly to the RILEM recommendation [16]. The room temperature during testing was $21^{\circ} \mathrm{C}$ and a relative humidity at around $50 \%$.

\subsection{Recorded loading curves}

The measured data were recorded by means of a state-of-the-art data acquisition system. Since the test configuration combines two loading mechanisms (the splitting of the specimen by horizontal forces induced by the wedge imposition from the top side, and the bending due to vertical component of the loading force, if two supports are employed), displacements corresponding to either of this loading component have to be measured. Thus, the crack mouth opening displacement $(C M O D)$ has been recorded via a linear variable differential transformer (LVDT) fixed on both sides of the specimen at the points of the splitting force imposition (and the average value from these two displacement transducers were considered for further processing) and one LVTD has measured the mid-span deflection $d$ (a pure value was measured by using an external frame holding the transducer). From the measured vertical load $P_{\mathrm{v}}$ the splitting (horizontal) force $P_{\mathrm{sp}}$ is calculated based on the loading wedge angle (more precisely according to the RILEM recommendation [19]).

Thus, two loading curves can be plotted for each test (except for the variant I, the classical WST with a single central support), and those are the $P_{\mathrm{sp}}-C M O D$ and $P_{\mathrm{v}}-d$. These loading diagrams are shown if Fig. 6 at the end of this paper. Note that the raw recorded data have been filtered and processed into a form convenient for further analysis. Moreover, some tests exhibited a rather unstable behaviour, especially in the variant IIIb. The descending branch of the loading curve consisted of only several recorded points. These data are included in the study; however, considered as much less reliable and, therefore, marked by an asterisk.

\section{FRACTURE PARAMETERS}

Two groups of fracture parameters relevant to this study are taken into account in the analysis presented in this paper. The first concerns the energy dissipated in the specimens during the fracture process under various geometry conditions. The work of fracture method is used in this context. In addition, the relationship between this energy dissipation and the crack-tip stress field distribution (determining the FPZ extent) is attempted to be described by parameter of constraint as it is used in two-parameter fracture mechanics of metals.

Basic fracture-mechanical evaluation is included in this paper; more detailed analysis via relevant fracture models is currently conducted and planned for publication.

\subsection{Fracture energy}

Areas under the filtered load-displacement curves were calculated providing thus the values of energy dissipated for the fracture of the specimen ligament - the work of fracture $W_{\mathrm{F}}$. These values were then specified (divided) by areas of the ligament (more precisely their projections to the crack plane, i.e. $B\left(W_{\text {ef }}-a\right)$ ), as is defined by the work of fracture method [16], which resulted in the value of fracture energy $G_{\mathrm{F}}$.

Mean values of the fracture energy corresponding to both loading force components are given in Tab. 3. Note that some of the $G_{\mathrm{F}}$ values are negative, which means that the displacement component corresponding to the loading force component has the opposite direction than the force. It was observed both in the $P_{\mathrm{sp}}-C M O D$ and the $P_{\mathrm{v}}-d$ diagrams (only one of them at the same time) shown in Fig. 6. This table summarizes 
also the total $G_{\mathrm{F}}$ value as a sum of the individual components.

Table 3: Mean values of fracture energy $G_{\mathrm{F}}$ determined from recorded loading curves for all considered geometry variants, notch lengths and wedge angles

\begin{tabular}{cccc}
\hline \multirow{2}{*}{$\begin{array}{c}\text { geometry } \\
\text { variant }\end{array}$} & \multicolumn{3}{c}{$G_{\mathrm{F}}\left(\mathrm{J} / \mathrm{m}^{2}\right)$} \\
\cline { 2 - 4 } & $P_{\mathrm{sp}}-C M O D$ & $F_{\mathrm{v}}-d$ & TOTAL \\
\hline $\mathrm{I}, \alpha_{1}$ & 74.26 & - & 74.26 \\
\hline $\mathrm{I}, \alpha_{2}$ & 72.88 & - & 72.88 \\
\hline $\mathrm{II}, \alpha_{1}$ & 107.35 & -11.14 & 96.21 \\
\hline $\mathrm{II}, \alpha_{2}$ & 105.54 & -10.27 & 95.27 \\
\hline $\mathrm{II}, \alpha_{3}$ & 82.48 & -9.22 & 73.26 \\
\hline $\mathrm{III}, \alpha_{1}$ & 152.95 & -25.21 & 127.74 \\
\hline $\mathrm{III}, \alpha_{2}$ & 144.64 & -25.56 & 119.08 \\
\hline $\mathrm{III}, \alpha_{3}$ & 102.72 & -16.91 & 85.81 \\
\hline $\mathrm{IIIb}, \alpha_{2}\left(15^{\circ}\right)$ & 222.10 & -47.27 & 174.83 \\
\hline $\mathrm{IIIb}, \alpha_{2}\left(30^{\circ}\right)$ & $-101.41^{*}$ & 151.67 & $50.26^{*}$ \\
\hline $\mathrm{III}, \alpha_{3}\left(30^{\circ}\right)$ & $-40.56^{*}$ & 78.42 & $37.86^{*}$ \\
\hline
\end{tabular}

\subsection{Constraint characteristics}

The two-parameter fracture mechanics concept used commonly for metals consists in the idea that the stress field in the vicinity of a crack tip is described by means of the
Williams expansion [16]. Originally, the infinite power series was derived for a homogenous elastic isotropic cracked body with an arbitrary remote loading; in the case of normal mode I loading conditions, it can be written in the following form:

$$
\sigma_{i j}=\sum_{n=1}^{\infty} A_{n} \frac{n}{2} r^{\frac{n}{2}-1} f_{i j}(n, \theta), \quad i, j \in\{x, y\}
$$

where $\sigma_{i j}$ represents the stress tensor components, $r$ and $\theta$ symbolize the polar coordinates (provided the centre of the coordinate system is at the crack tip and the crack faces lie on the negative $x$-axis), and $f_{i j}$ are known functions. In the case of two parameter fracture mechanics, the only unknown symbols in Eq. (1) (provided that the infinitive power series is truncated to two terms) are the coefficients $A_{1}$ (representing the stress intensity factor $K$ ) and $A_{2}$ (representing $T$-stress) - their values depend on the cracked specimen configuration and the load level.

Leevers and Radon [21] postulated the nondimensional biaxiality parameters $B_{1}, B_{2}$, from which the $K$-factor and $T$-stress are calculated in the following form:

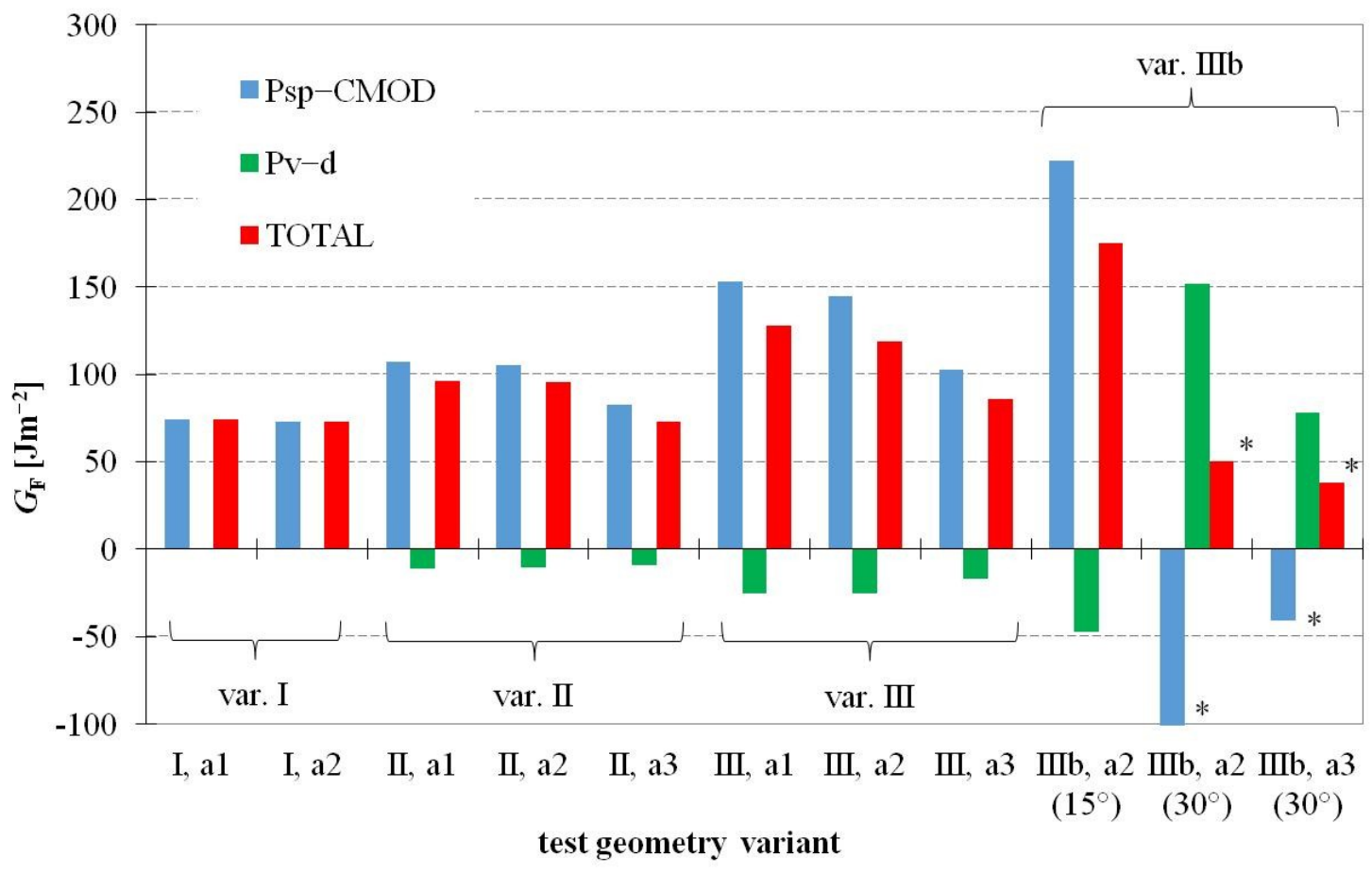

Figure 2: Comparison of $G_{\mathrm{F}}$ values for all considered geometry variants, notch lengths and wedge angles. 


$$
\begin{gathered}
K_{\mathrm{I}}=\sigma \sqrt{\pi a} B_{1}(\alpha), \\
T=\frac{K_{\mathrm{I}} B_{2}(\alpha)}{\sqrt{\pi a}}=\sigma B_{1}(\alpha) B_{2}(\alpha),
\end{gathered}
$$

where $\sigma$ represents the applied load, $a$ is the relative crack length. The dimensionless functions $B_{1}(\alpha), B_{2}(\alpha)$ are usually determined from results of FEM calculations. Note that the change in constraint parameters caused by variation of the specimen geometry, crack (notch) lengths, loading conditions and specimen thickness has a considerable influence on the determined value of fracture toughness of metallic materials. It is wellknown that one of the most common criterions for validation of the experimental measurement of the fracture toughness is connected with the size of the crack tip plastic zone which depends on the degree of the crack tip constraint, see [22]-[28]. For the example of a standard three-point bending of a single edge notched specimen (SEN-TPB), these changes are illustrated in Fig. 3. For a load characterized by the same value of $K_{\mathrm{I}}$, the crack-tip plastic zone varies in both the size and the shape with the change of the constraint characteristics. The biaxiality factor $B_{2}$ is negative for the relative crack length $\alpha=0.15$, which results in a large plastic zone oriented forward, in contrast to high positive values of $B_{2}$ (e.g. for $\alpha=0.88$ ) resulting in small plastic zone oriented backward.

The test geometries studied in this contribution were designed to cover a wide range of crack-tip constraint, from the high level (e.g. var. I) to its low level (var. IIIb), see the graph in Fig. 4 right. Here again, the standard SEN-TPB configuration is included for comparison. The calibration curves plotted in Fig. 4 were determined from FEM results using direct methods [29]-[31] and published (including coefficients of also higher order terms of the series in [32]).

Note that other available test geometries providing a low level of constraint, typically the tensile tests of notched specimens, are rather straightforward to the fracture parameters evaluation; however, very demanding on their correct execution.

\section{SIMULATIONS}

\subsection{FE model, constitutive model}

The ATENA 2D computational tool [33], which is based on FEM with implementations of nonlinear fracture-mechanics and plasticity approaches, was used for numerical simulations of the tests. This virtual testing was performed in order to estimate the feasible ranges of the specimen shape proportions $(W / L, S / L, a / W)$ for real testing.

A non-linear (fracture-plastic) material model for concrete was used, combining the constitutive models for tensile (fracture) and compressive (plastic) failure behaviour. The fracture model is based on the classical formulation of orthotropic smeared cracks

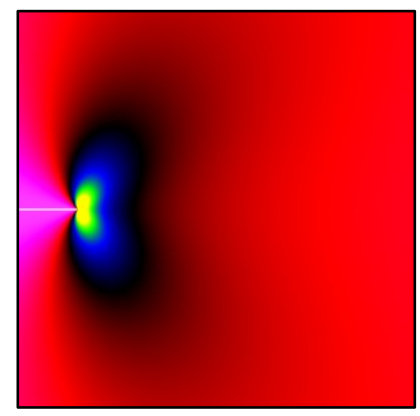

$\alpha=0.15$

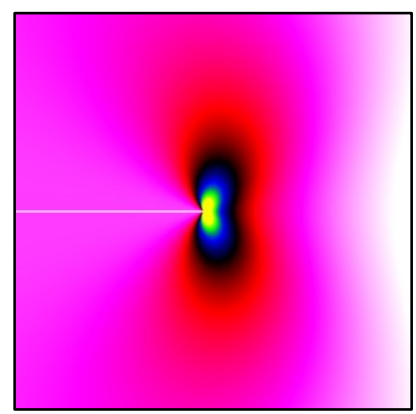

$\alpha=0.48$

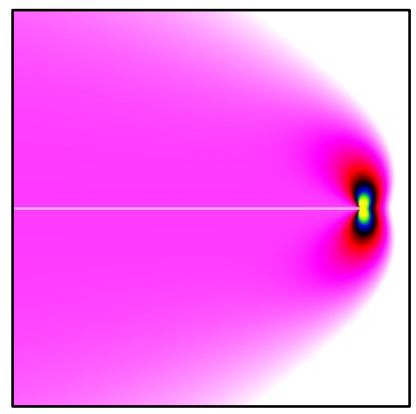

$\alpha=0.88$

Figure 3: Variations in crack-tip constraint for SEN-TPB specimen loaded with the same value of $K_{\mathrm{I}}$ resulting in differences in $\sigma_{y y}$ stress field: from low constraint (left) to high constraint (right, compare to SEN-TPB curve Fig. 4 right). 

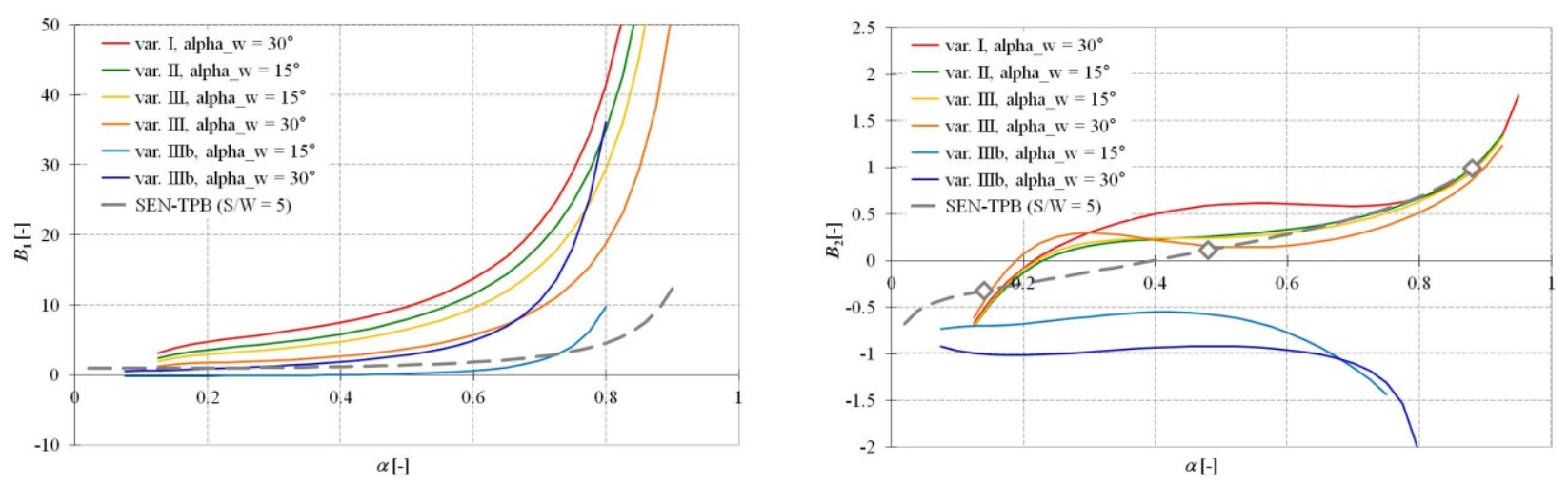

Figure 4: Calibration curves for $K_{\mathrm{I}}\left(B_{1}\right)$, left, and $T$-stress $\left(B_{2}\right)$, right (adopted from [32]); curves for standard SEN-TPB test are included for comparison (points on SEN-TPB curve in graph on the right correspond to stages depicted in Fig. 3).

with crack band model implementation (cohesive crack model) with rotating and/or fixed cracks. Rankine criterion is used for tensile failure. The plasticity model enabling softening (hardening) is based on MenétreyWillam failure criterion. The created FE models of the performed test configurations consist of the fracture-plastic material model (3D Nonlinear Cementitious 2) used for the specimen body (made of concrete with cubic compressive strength $f_{\text {cu }}=32 \mathrm{MPa}$, Young's modulus $E=33.1 \mathrm{GPa}$, Poisson's ratio $v=0.2$, compressive strength $f_{\mathrm{c}}=27.2 \mathrm{MPa}$, tensile strength $f_{\mathrm{t}}=2.42 \mathrm{MPa}$, fracture energy $G_{\mathrm{f}}=60.5 \mathrm{~N} / \mathrm{m}$ and Hordijk's exponential softening), the elastic isotropic material model is used for steel loading platens $(E=210 \mathrm{GPa}$ and $v=0.3)$ and the interface material model (with Coulomb friction) is used for the modelling of the concrete/steel interface. The problem was modelled under the plane strain conditions.

The external loading imposed to the specimen via the loading wedge and steel platens (with roller bearings) inserted in the groove in the specimen was modelled as close to the reality as possible, therefore, a special FE model was created imposing the displacement at the contact between the wedge and the roller bearing through a very long and stiff tie (modelled as an external cable). The created FE models are illustrated in Fig. 5.

All dimensions and geometry parameters were modelled according to the nominal values (see Tab. 1 and 2).

\subsection{Crack-tip stress fields}

Distribution of stress field in the specimen ligament can be compared based on iso-stress contour plots and possibly stress profiles across the specimen. Such an interpretation of the crack opening stress component $\sigma_{y y}$ (with its profile along the ligament) is displayed for all the considered geometry variants in Fig. 7.

Stress contours in the left and middle column represent the stages of fracture process corresponding to one half of the peak load at the ascending branch (the end of elastic regime, the crack starts to propagate from notch(es)), and at the peak load (corresponding to a critical length of an effective crack), respectively.

In the right column, iso-strain contours of fracture strain $\varepsilon_{\text {cr }}$ at half the peak load at the descending branch are displayed. From these diagrams a sort of estimates of the fracture process zone can be obtained.

\section{DISCUSSION AND CONCLUSIONS}

The conducted experiments on notched specimens subjected to combined wedgesplitting/bending test, both real and virtual, provided a set of unique data that are worth deeper analysis. This paper presents only partial evaluation. However, from results presented above the main following facts can be emphasized: 


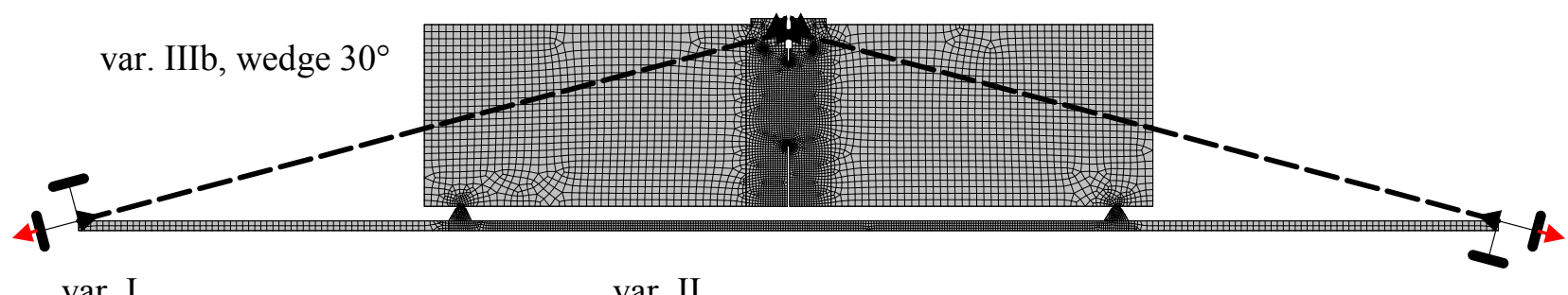

var. I

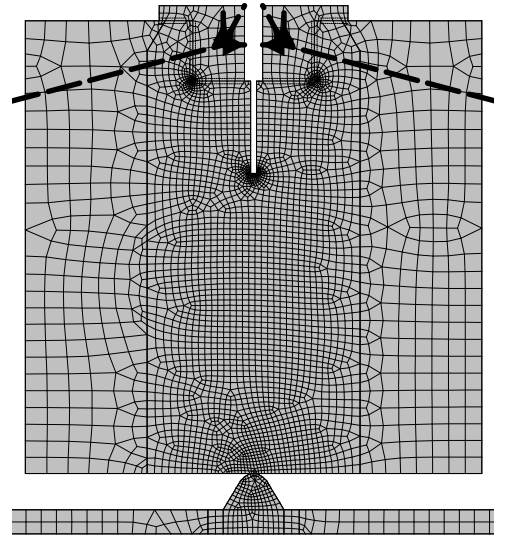

var. II

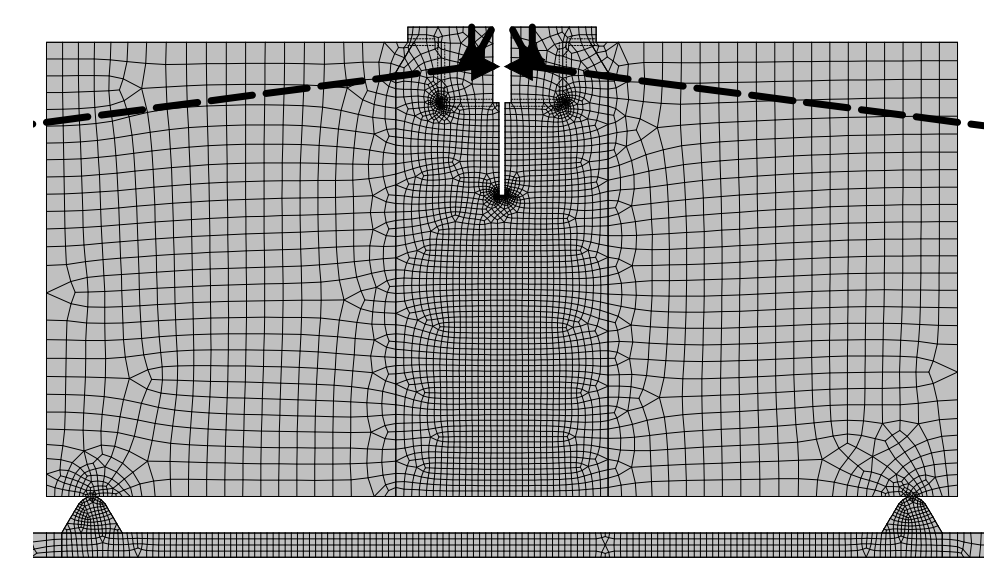

Figure 5: Created FE models: selected variants with indication of the loading imposition (top) and detail of the FE mesh in the specimen (bottom).

- The amount of energy dissipated for breaking the specimen ligament varies with alteration of the geometry case. This amount, if expressed in terms of the fracture energy $G_{\mathrm{F}}$ (according to RILEM) plotted in Fig. 2, exhibits tendency to increase its value with decreeasing crack-tip stress constraint. This is true for variants I to III. For quantification of the constraint phenomenon, the biaxiality factor $B_{2}$, commonly used in (two-parameter) fracture mechanics of metals, is adopted in this work.

In addition, the $G_{\mathrm{F}}$ value decreases with increasing crack length. This fact is in agreement with the previous statement, since $B_{2}(\alpha)$ curves rise for all these three geometry variants in the area of long relative cracks. Such a trend has been observed in many experiments dealing with high-constrained test geometries, e.g. SEN-TPB or WST geometry (which is true at least for small relative ligament lengths), as has been published in e.g. [4],[8].

Variant IIIb fits into this trend only partially (only for the set IIIb, $\alpha_{2}$, wedge $15^{\circ}$ ). The other results corresponding to this geometry variant are regarded as much less reliable due to the unstable manner of the observed test progress (resulting in sparse record of data on the descending branch of the loading curve).

- From the FEM simulated stress profiles along the specimen width at the end of the elastic regime it is obvious that the selected geometry variants provide a considerable (and desired) variety in the stress field distribution. It can be seen in Fig. 7 left that the almost pure bending in variant I changes to tension with moderate eccentricity in variant III, and finally to tension with low eccentricity (or even pure tension) in variant IIIb (depending on the notch length and wedge angle).

- The trend of the iso-stress contours displayed in the middle column in Fig. 7 suggests (based on the widths/shapes of the coloured fields) that the extent of the zone of material damage must depend on the stress field, particularly on the constraint of this field (possibly characterized by parameters of multi-parameter crack-tip field description). However, a judgement on the direction of the 
tendency is ambiguous - red areas of lower stress level rather increase with decreasing constraint, on the other hand the blue areas of high stress level (close to localization of the deformation and initiation and propagation of cracks) decrease with the decreasing constraint.

- From the contour plots of fracture strain calculated by the used software (see the right column of Fig. 7), it is also very tricky to assess the relationship between the FPZ extent and the stress constraint. If the whole area of the inelastic strains was considered, then the largest zone is observed in variant I. However, if the area with strains higher than $1.0 \times 10^{-3}$ was taken for comparison, then variants II and III show localization in a wider band (or several bands) than that for variant I. Further comparison to variant $\mathrm{IIIb}$ is not straightforward, because the specimens have much shorter ligaments.

The designed novel fracture test configuration combining the wedge splitting and bending loading geometries provided valuable data for investigation of the relationship between the characteristics of the zone of material failure and the energy dissipated within this zone during fracture process. Further deeper analysis of the obtained experimental data as well as detailed numerical simulations of the observed phenomena by proper models are planned for future research or are already under processing by the authors collective.

\section{ACKNOWLEDGEMENTS}

Financial support from the Czech Science Foundation (project No. 15-07210S) is gratefully acknowledged.

\section{REFERENCES}

[1] Veselý, V., Frantík, P. 2014. An application for the fracture characterization of quasi-brittle materials taking into account fracture process zone influence. $A d v$. Eng. Softw., 72: 66-76.

[2] Frantík, P., Veselý, V., Keršner, Z. 2013. Parallelization of lattice modelling for estimation of fracture process zone extent in cementitious composites. Adv. Eng. Softw., 60-61: 48-57.

[3] Veselý, V., Frantík, P. 2010. Reconstruction of fracture process zone during tensile failure of quasi-brittle materials. Appl. Comp. Mech., 4: 237-250.

[4] Duan, K., Hu, X.-Z., Wittmann, F.H. 2002. Explanation of size effect in concrete fracture using non-uniform energy distribution. Mater. Struct., 35: 326-331.

[5] Duan, K., Hu, X.-Z., Wittmann, F.H. 2003. Boundary effect on concrete fracture and non-constant fracture energy distribution. Eng. Fract. Mech., 70: 22572268.

[6] Hu, X.-Z., Wittmann, F.H. 1992. Fracture energy and fracture process zone. Mater. Struct., 25, 319-326.

[7] Hu, X.-Z., Duan, K. 2004. Influence of fracture process zone height on fracture energy of concrete. Cem. Concr. Res., 34, 1321-1330.

[8] Karihaloo, B.L., Abdalla, H.M., Imjai, T. 2003. A simple method for determining the true specific fracture energy of concrete. Mag. Concr. Res., 55: 471-481.

[9] Hoover, Ch.G., Bažant, Z.P., Vorel, J., Wendner, R., Hubler, M.H. 2013. Comprehensive concrete fracture tests: Description and results. Eng. Fract. Mech., 114, 92-103.

[10]Mihashi, H., Nomura, N. 1996. Correlation between characteristics of fracture process zone and tensionsoftening properties of concrete. Nucl. Eng. Design, 165: 359-376.

[11] Otsuka, K., Date, H. 2000. Fracture process zone in concrete tension specimen. Eng. Fract. Mech., 65, 111-131.

[12] Vidya Sagar, R., Raghu Prasad, B.K. 2009. AE energy release during the fracture of HSC beams. Mag. Concr. Res., 61(6), 419-435.

[13] Muralidhara, S., Raghu Prasad, B.K., Eskandari, H., Karihaloo, B.L. 2010. Quantification of fracture process zone size and true fracture energy using acoustic emission. Constr. Build. Mat., 24: 479- 
486.

[14]Tschegg, E.K. 1986. Equipment and appropriate specimen shapes for tests to measure fracture values. Austrian Patent AT No. 390328, Austrian Patent Office, Austria.

[15]Linsbauer, H.N., Tschegg, E.K. 1986. Fracture energy determination of concrete with cube-shaped specimens. Zement und Beton, 31: 38-40.

[16]RILEM Draft Recommendation TC 50FMC 1985. Determination of the fracture energy of mortar and concrete by means of three-point bend test on notched beams. Mater. Struct., 18, 285-290.

[17] Seitl, S., Korte, S., De Corte, W., Boel, V., Sobek, J., Veselý, V. 2014. Selecting a suitable specimen shape with low constraint value for determination of fracture parameters of cementitious composites. Key Eng. Mat., Vols. 577-578, 481-484.

[18] Veselý, V., Frantík, P., Sobek, J., Malíková, L., Seitl, S. 2015. Multi-parameter crack tip stress state description for evaluation of nonlinear zone width in silicate composite specimens in component splitting/bending test geometry. Fatigue Fract. Eng. Mater. Struct., 38(2): 200-214.

[19]RILEM Report 5 1991. Fracture Mechanics Test Methods for Concrete, S.P. Shah, Al. Carpinteri (eds.). Chapman \& Hall, London.

[20]Williams, M. L. 1957. On the stress distribution at the base of a stationary crack. ASME J. Appl. Mech., 24: 109-114.

[21]Leevers, P. S., Radon, J. C. 1982. Inherent stress biaxiality in various fracture specimen geometries. Int. J. Fract., 19: 311325 .

[22] Sorem, W.A. Dodds, R.H. Rolfe, S.T. 1991. Effects of crack depth on elastic plastic fracture toughness, Int. J. Fract., 47: 105-126.

[23]Liu, S., Chao, Y.J. 2003. Variation of fracture toughness with constraint. Int. J. Fract., 124: 113-117.

[24]Xhu, X.K., Chao, Y.J. 2005. Specimen size requirements for two-parameter fracture toughness testing. Int. J. Fract.
135: 117-136.

[25] Tanaka, T. 2010. Experimental T33-stress formulation of test specimen thickness effect on fracture toughness in the transition temperature region. Eng. Fract. Mech., 77: 867-877.

[26]Kumar, B, Chitsiriphanit, S., Sun, C.T. 2011. Significance of K-dominance zone size and nonsingular stress field in brittle fracture. Eng. Fract. Mech., 78: 20422051.

[27] Wang, Z.X., Shi, H.-J., Lu, J. 2008. Size effects on the ductile/brittle fracture properties of the pressure vessel steel 20 g. Theor. Appl. Fract. Mech., 50: 124131.

[28]Pluvinage, G., Capelle, J., Hadj Méliani, M. 2014. A review of fracture toughness transferability with constraint and stress gradient. Fatigue Fract. Eng. Mater. Struct., 37: 1165-1185.

[29]Tan, C. L., Wang, X. 2003. The use of quarter-point crack-tip elements for $T$ stress determination in boundary element method analysis. Eng. Fract. Mech., 70: 2247-2252.

[30] Yang, B., Ravi-Chandar, K. 1999. Evaluation of elastic $T$-stress by the stress difference method. Eng. Fract. Mech., 64: 589-605.

[31] Ayatollahi, M.R., Nejati, M. 2011. An over-deterministic method for calculation of coefficients of crack tip asymptotic field from finite element analysis. Fatigue Fract. Eng. Mater. Struct., 34: 159-176.

[32] Sobek, J., Veselý, V. 2016. Shape and compliance functions of splitting/bending test specimens for determination fracture parameters of quasi-brittle materials. Accepted to 33er Encuentro del Grupo Español de Fractura, San Sebastián, Spain, 9-11 March 2016.

[33] Červenka, V. et al. 2011. ATENA Program Documentation, Theory and User Manual. Cervenka Consulting, Prague. 


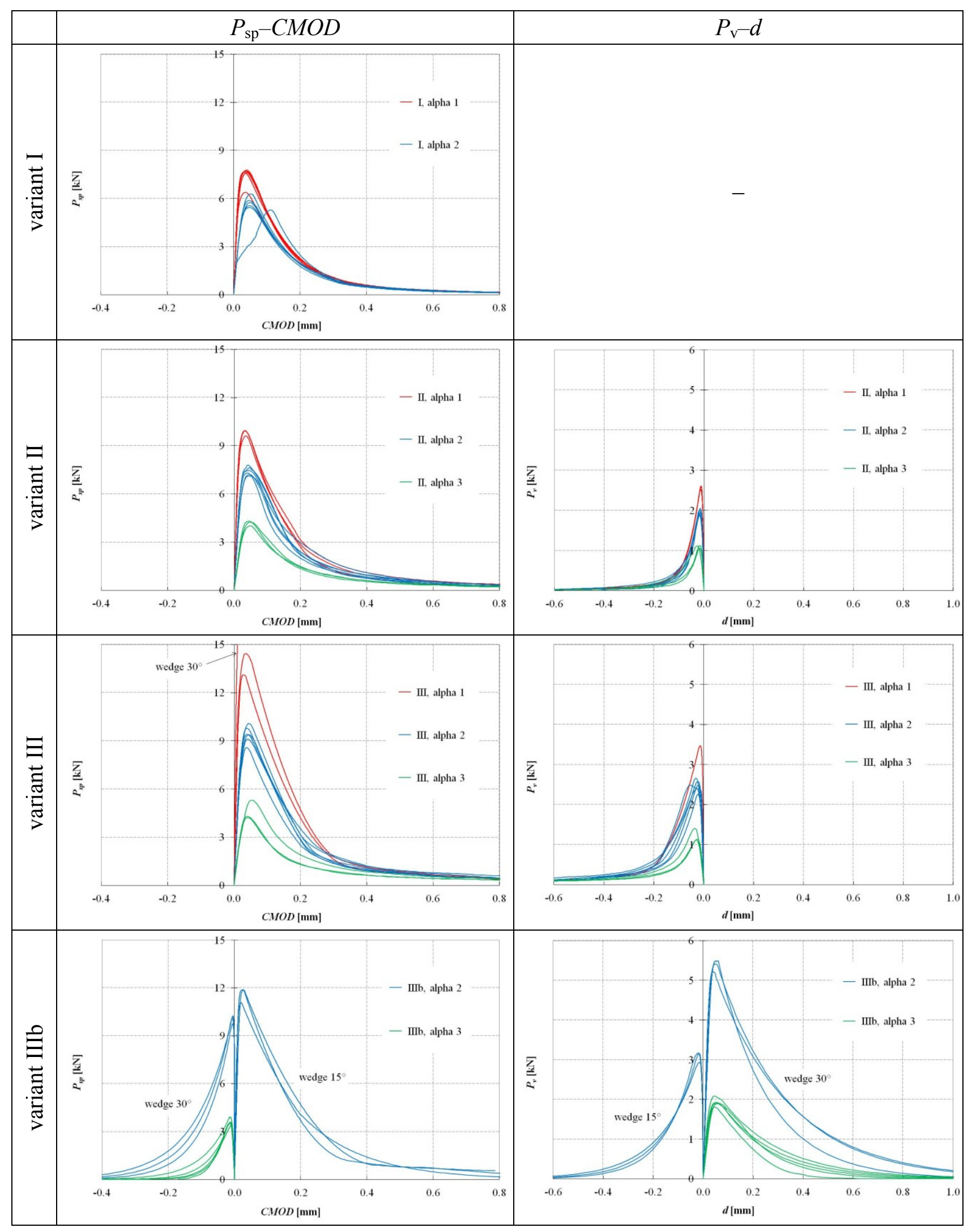

Figure 6: Recorded loading curves. 


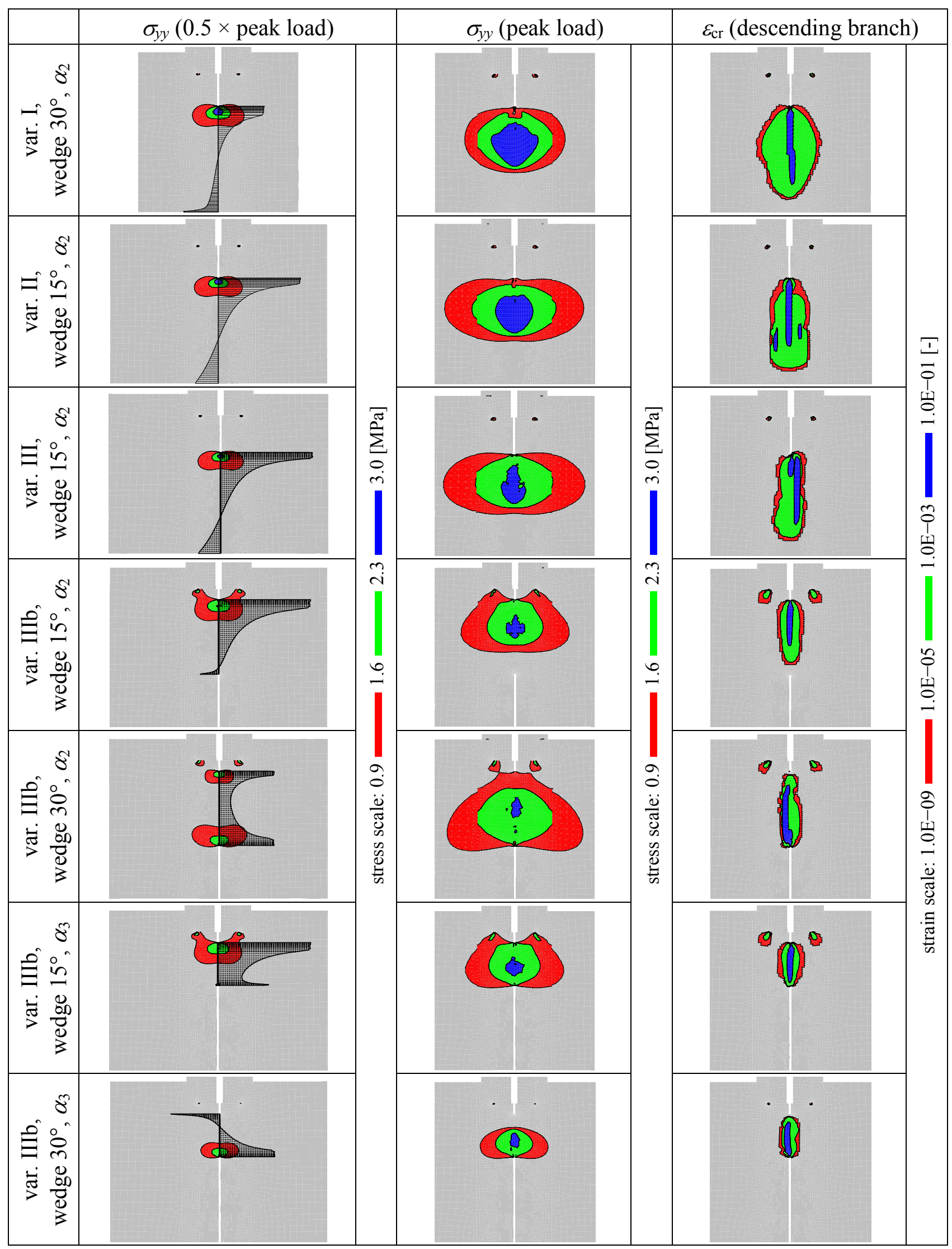

Figure 7: Simulated fields: crack opening stress $\sigma_{y y}$ at half the peak load (left, with stress profiles) and at the peak load (centre), fracture strain $\varepsilon_{\mathrm{cr}}$ at half the peak load at descending branch. 